\title{
Automation of monitoring and diagnosing the technical condition of torpedo ladle cars
}

\author{
Vitaliy Yemelyanov ${ }^{1, *}$, Tatiana Tochilkina $^{1}$, Alexey Nedelkin ${ }^{2}$ and Evgeny Shved ${ }^{2}$ \\ ${ }^{1}$ Financial University under the Government of the Russian Federation, 49 Leningradsky Prospekt, \\ Moscow, 125993, Russia \\ ${ }^{2}$ Plekhanov Russian University of Economics, 36, Stremyanny Lane, Moscow, 117997, Russia
}

\begin{abstract}
The paper presents data on the problem of monitoring and diagnosing the technical condition of torpedo ladle cars at the iron and steel works. The structure of technology for automated monitoring and diagnosing the technical condition of torpedo ladle cars has been developed and described, as a system-organized sequence of operations performed with the information on the state of the torpedo ladle cars applying the proposed methods. There has been developed software to implement the operations of information processing for torpedo ladle cars and to support decision-making on selecting their operational mode.
\end{abstract}

\section{Introduction}

In the course of industrial production, dangerous and critical production facilities and machinery are used. Lined equipment, including torpedo ladle cars, hot-metal cars and steel ladles, is considered to be critical equipment at heavy industry and machinery building facilities [1-2]. In order to prevent accidents with such type of equipment and maintain industrial safety at the production facility, a growing number of diagnostic operations and technologies to control technical condition of lined equipment are applied in production units [3-5], which, in turn, require development of new and improvement of existing technical means and information technologies.

Nowadays there are different automated systems that possess a wide range of functions to diagnose and monitor the condition of critical equipment; however, as a number of sources claim [6-8], existing systems do not provide diagnostics of the given lined equipment in the real-time mode without stopping its exploiting. It should be mentioned that modern automated systems are unable to provide complete complex (qualitative and quantitative) automated evaluation of the lining condition, which leads to a low level of objectiveness and quality of the decisions taken while exploiting the equipment. That is why, scientific research to create new systems and technologies for automated monitoring and diagnosing lined equipment is relevant.

\footnotetext{
*Corresponding author: v.yemelyanov@gmail.com
} 


\section{Technology for automated monitoring and diagnosing the technical condition of torpedo ladle cars}

The paper provides a technology for automated monitoring and diagnosing the technical condition of the torpedo ladle cars, in the form of a system-organized sequence of operations performed with the information about the technical condition of the torpedo ladle cars using the methods proposed by the authors.

Using the graphical language IDEF0, the proposed technology is displayed as a set of interrelated functional blocks. Thus, the technology for automated monitoring and diagnosing the technical condition of torpedo ladle cars is presented in the form of the following main stages of its functioning:

1. Forming images of torpedo ladle cars thermograms.

2. Monitoring and multiple diagnostics of the lining condition in the process of a single cycle of the torpedo ladle car operation.

3. Compiling the monitoring and diagnostic report.

4. Supporting decision-making for the selection of the operational mode of torpedo ladle cars based on monitoring and diagnostic results.

5. Compiling the final report on the operation of the fleet of torpedo ladle cars for a single cycle of use.

The IDEF0-diagram of this technology was implemented in the ErWin tool environment. The results are shown in Figure 1.

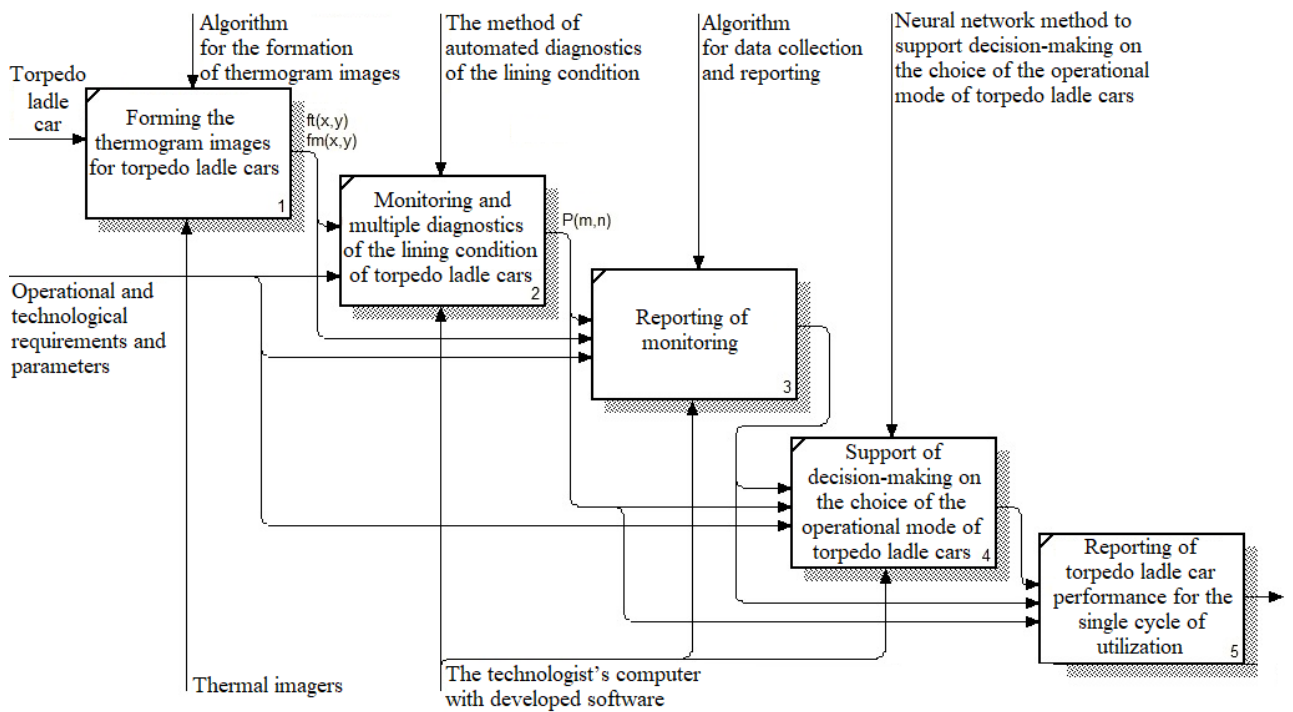

Fig. 1. IDEF0-diagram of the proposed technology for automated monitoring and diagnosing the technical condition of torpedo ladle cars.

Let us consider the proposed technology for automated monitoring and diagnosing in details.

As a result of the first operation of proposed technology, primary information on the technical condition of the torpedo ladle cars is collected. It consists in the formation of images of thermograms of torpedo ladle cars using thermal imagers.

Primary data processing starts to be performed at the second stage of technology. To provide 2 operations of proposed technology, the authors [9] developed a neural network method for automatic diagnostics of the lining condition, the specific feature of which is neural network segmentation and recognition of thermograms of torpedo ladle cars to 
determine the areas of the lining burnout. It allows determining automatically the actual condition of torpedo ladle cars and, as a result, to prevent their failure. The method of automated diagnostics of the lining condition of torpedo ladle cars suggested by the authors makes it possible to increase the reliability of determining lining burnt out zones in comparison with the existing methods for diagnosing lined equipment from $86 \%$ to $97 \%$, which is confirmed by the information given in [9-10].

The third and fifth operations of the proposed technology are designed to summarize information on the operation of torpedo ladle cars with the compilation of reports concerning the technical condition of the torpedo ladle cars lining and the recommended modes of their operation.

During the fourth operation of the technology, processing of the obtained information on the status of torpedo ladle cars continues to evaluate automatically the mode of their operation. To provide the fourth operation of the technology, the authors in this paper propose a neural network method for supporting decision-making in respect to selection of the operational mode for the torpedo ladle cars as described below.

In the process of monitoring and technical diagnostics of the condition of the torpedo ladle cars, the compulsory operation is the evaluation of the operational mode of the diagnosed equipment taking into account the revealed defects in the lining. In practice, a technologist based on his personal experience performs this operation manually. It increases subjectivity and leads to significant errors. It is proposed to automate the mode evaluation operation. The following method is offered for this purpose. The method of supporting decision-making in respect of the selection of the operational mode for torpedo ladle cars consists of three main stages.

At the first stage of the method, a number of factors are formed and coded. On this basis, the technologist makes a decision to transfer the torpedo ladle cars to the relevant operating mode. The main factors influencing the technologist's decision on the operational mode of torpedo ladle cars are 5 sets.

1. Set "Factor A" -performance characteristics of the torpedo ladle cars (the number of liquid metal castings produced or the utilization period; maximum permissible values: the number of castings or the utilization period and the period of liquid metal in a torpedo ladle car or time of continuous operation; actual values: the period of liquid metal in a torpedo ladle car or time of continuous operation);

2. Set "Factor B" - liquid metal specific features (maximum permissible and actual weights (mass) of the liquid metal; maximum permissible and actual temperatures of the liquid metal);

3. Set "Factor C" - specific features of the lining for the torpedo ladle car (maximum permissible and actual numbers of the damaged sections of the lining; the maximum permissible and actual depths of the lining burnout; the maximum permissible and actual areas of the lining burnout);

4. Set "Factor D" - specific features of the torpedo ladle car housing (permissible and actual conditions of the torpedo ladle car housing);

5. Set "Factor E" - features of the production process (the amount of planned liquid metal for transportation; actual transported amount of the liquid metal).

At the second stage of the method, a criterial assessment of the condition of the factors is made at the time of making a decision to transfer the torpedo ladle cars to the appropriate operating mode. Every factor is characterized by an evaluation of its sub-factors. However, the set of production regulations is not sufficient to determine the operational mode of the torpedo ladle car, as these regulations take into account only the quantitative condition of the lining, but they do not consider its qualitative condition. A criterion assessment of the factors of the condition of torpedo ladle car is required to identify the possible outcomes in 
evaluating the current condition. To evaluate the calculated outcomes, it is proposed to use a neural network.

At the third stage of the method, the neural network estimation of the factors is performed, with the definition of the specific operational mode of the torpedo ladle cars. The use of a neural network in this case is justified by the fact that it is easy to adapt this method to any lined equipment (ladle cars, steel ladles, etc.) by training the neural network the number of outcomes and operational modes that are characteristic for the relevant type of the lined equipment (torpedo ladle cars, steel ladle, etc.).

The structure of the neural network for determining the operational mode of torpedo ladle cars is multilayer perceptron [9]. The input of the neural network receives the values of the factors. In the hidden layer of the neural network, the outcomes are evaluated based on the factors formed, taking into account the qualitative condition of the lining. The output layer of the neural network consists of one neuron that performs the classification of the operating modes of torpedo ladle cars. In this case, the fragmentation of the effect of factors on the outcome is carried out in the hidden layer, i.e. input values are supplied to the input of not all the neurons of the hidden layer. Required input values are given only to those hidden layer neurons that are responsible for evaluating the relevant outcome.

For the proposed structure of a neural network, the use of a sigmoid activation function is offered. The network was trained according to the back propagation algorithm [10]. The training sample comprised 620 sets of factors, compiled for the period 2014-2016 for the torpedo ladle cars of PM350 type, used at Alchevsk Iron and Steel Works. As a control and test samples, 580 sets of factors were used for every sample, affecting the possibility of using PM350 torpedo ladle cars at Alchevsk Iron and Steel Works.

The support of decision making in the process of monitoring and diagnostics of the torpedo ladle cars is the automatic determination of the operating mode applying the proposed method. Based on the method, the technologist decides what operational mode for the torpedo ladle cars to choose.

\section{Developed software for automated monitoring and diagnosing the technical condition of the torpedo ladle cars}

For the purpose of instrumental support of the proposed technology, a client-server software LE_Diagnostics (Figure 2) was designed to implement and maintain the developed technology methods. The software implements a graphical user interface for determining the current technical status of torpedo ladle cars, providing input of the initial data, parameters for monitoring and diagnosing, and displaying the results obtained. The developed software comprises a registered thermogram image analyzer.

The functions of the LE_Diagnostics tool in analysis mode are as follows:

1. Input of the thermogram image of the torpedo ladle car (the first operation of the proposed technology);

2. Preliminary processing of the thermogram image (the second operation of the proposed technology);

3. Recognition of zones of the lining burnout in the thermogram image (the second operation of the proposed technology);

4. Evaluation of the operational mode of torpedo ladle cars, due to the implementation of the proposed decision support method (the fourth operation of the proposed technology);

5. Formation of conclusions and recommendations for the operation of torpedo ladle cars (the third and fifth operations of the proposed technology);

6. Sending the results of monitoring and diagnostics to the server in the workshop. 


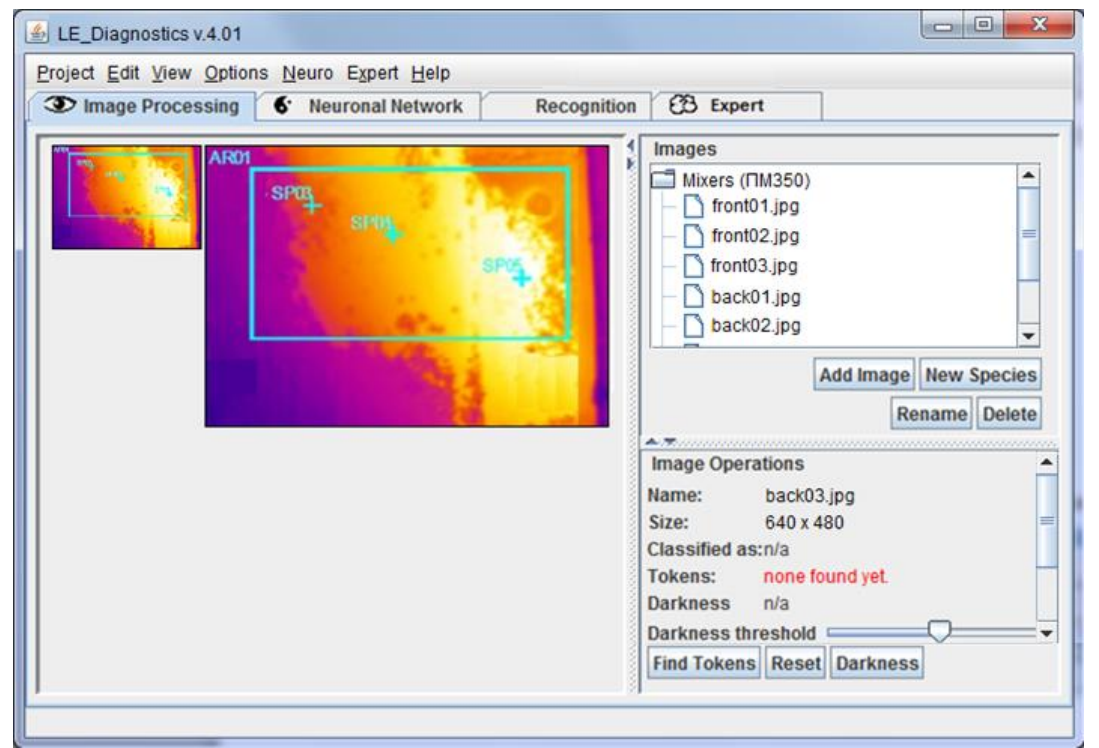

Fig. 2. Developed software (LE_Diagnostics) implementing the stages of the proposed technology

In the training mode, the LE Diagnostics tool supports:

1. Input by the technologist of the base of factors reference values influencing the possibility of using torpedo ladle cars;

2. Input by the technologist of the base of standard thermograms of torpedo ladle cars;

3. Selection of neural network architecture for thermogram recognition;

4. Training of neural networks based on input standards;

5. Construction of graphs of training errors and classification of neural networks;

6. Maintaining the parameters of the trained neural network for further recovery on demand and carrying out a new analysis on its basis.

The developed software is implemented and applied in the technical diagnostics of torpedo ladle cars PM350 in the weighing shop at Alchevsk Iron and Steel Works.

\section{Conclusion}

The following scientific and practical results were received:

1. The technology for automated monitoring and diagnosing the technical condition of torpedo ladle cars was suggested as a system-organized sequence of operations performed on information concerning the condition of torpedo ladle cars applying the methods proposed in the paper.

2. For the purpose of tool support of the proposed technology, client-server software was developed. It implements the methods of proposed technology offered by the authors for automated monitoring the technical condition and supporting decision-making in the operation of torpedo ladle cars.

\section{References}

1. T. Fredman, J. Torrkulla, H. Saxe'n, Metallurgical And Materials Transactions B, 30B, 323-330, (1999) 
2. N. Schmitt, F. Hild, E. Blond, Advances in refractories for the metallurgical industries, IV, 39-51, (2004)

3. V. Petkov, M. Hadjiski, K. Boshnakov, E. Mihailov, Cybernetics and information technologies, 13(2), 66-76, (2013)

4. C. Almeida, W. Camihas, A. Braga, V. Padiva, H. Martins, R. Torres, Proc. of SPIE, 5782, (2005)

5. Y. Sun, D. Zhang, M. Yang, Y. Tang, Proc. Int. Conf. on Mechanic Automation and Control Engineering, 2589-2592, (2012)

6. A.V. Zabolotsky, Journal of Engineering Physics and Thermophysics, 84(2), 342-347, (2011)

7. Y. Gordon, S. Kumar, M. Freislich, Y. Yaroshenko, Steel in Translation, 45(9), 627634, (2015)

8. M. Fidali, Proc. of the 9th Int. Conf. on Quantitative Infrared Thermography, 123-130, (2008)

9. V.A. Yemelyanov, N.Y. Yemelyanova, A.A. Nedelkin and M.V. Zarudnaya, IOP Conference Series: Materials Science and Engineering, 327(2), 022107, http://dx.doi.org/10.1088/1757-899X/327/2/022107, (2018)

10. V. Yemelyanov, N. Yemelyanova and A. Nedelkin, MATEC Web of Conferences, 172, 04001, https://doi.org/10.1051/matecconf/201817204001, (2018) 